\title{
El reconocimiento del conflicto armado en el Perú. La inserción del Derecho Internacional Humanitario en el Informe Final de la Comisión de la Verdad y Reconciliación Nacional
}

Elizabeth Salmón Gárate*

\section{Introducción}

El Informe final de la Comisión de la Verdad y Reconciliación (en adelante CVR) suscitó un encendido debate en torno a varios temas que estuvieron archivados durante un buen tiempo en las agendas de diversas personalidades nacionales. Este solo hecho, más allá de las posiciones personales, constituye sin duda un logro del informe.

Uno de los temas planteados es el referido a la calificación de conflicto armado interno para la situación de violencia que se desencadenó en el Perú y las supuestas consecuencias que de ella se derivan. En este sentido, se señaló que ello podría implicar el reconocimiento de Sendero Luminoso y el MRTA como grupos beligerantes, la atribución a sus miembros del estatuto de prisioneros de guerra y el reclamo de una amnistía para sus detenidos. Ninguno de estos temores tiene asidero ni en el marco del Derecho internacional ni tampoco en el propio Informe Final. Más bien, su alegación se vincula a raíces más profundas que tienen que ver, entre otras razones, con la desconfianza y desconocimiento que han acompañado al Derecho Internacional Humanitario (en adelante DIH) en nuestro medio. Por esto, las siguientes líneas buscan indagar algunas nociones del $\mathrm{DIH}$, pero sobre todo en la forma cómo el propio Informe Final de la CVR aborda esta parte poco pacífica del derecho internacional.

* Profesora Asociada del Departamento de Derecho. 


\section{La definición y función del derecho internacional humanitario}

El DIH, o también denominado ius in bello, no permite ni prohíbe los conflictos armados - tanto internacionales como internos-, sino que, frente a su desencadenamiento, se aboca a fin de humanizarlos y limitar sus efectos a lo estrictamente necesario. Se trata de un conjunto de normas, de origen convencional o consuetudinario, cuya finalidad específica es solucionar los problemas de índole humanitaria directamente derivados de los conflictos armados y que, por razones humanitarias, restringe la utilización de cualquier método o medio de combate. ${ }^{1}$ Pretende un equilibrio entre las necesidades militares y el principio de humanidad, es decir, entre lo que es necesario para vencer al adversario y lo que simplemente denota crueldad. ${ }^{2}$ En suma, oponer la civilización" de los límites ante el desenfreno de la barbarie que pueden suponer, per se, los enfrentamientos armados. ${ }^{3}$

En este sentido, el vasto número de normas que lo conforman buscan, de un lado, proteger a las víctimas de los conflictos armados y, de otro, limitar los medios y métodos de combate, vale decir, proteger la dignidad e integridad de las personas en el marco de los enfrentamientos armados. Siguiendo esto, el capítulo 4 del Informe Final de la CVR (La Dimensión Jurídica de los Hechos) plantea una definición del DIH que, en su acepción contemporánea:

[...] comprende lo que fueron en su origen dos ramas distintas del llamado Derecho de la Guerra. Estas son: el Derecho de la Haya y el Derecho de Ginebra, relativo el primero a las reglas que rigen el desarrollo de las hostilidades y el segundo, a las reglas humanitarias que deben aplicar las partes en conflicto en su relación con las personas que no intervienen directamente en las hostilidades, con el enemigo rendido o fuera de combate y con lo que se refiere a los bienes de carácter no militar. $^{4}$

Cabe señalarse que este tipo de definiciones no es ajeno a otros trabajos de comisiones de la verdad. Así, por ejemplo, la Comisión para el Esclarecimiento Histórico de Guatemala definió el DIH afirmando que:

PICTET, Jean. «El Derecho internacional humanitario: Definición». En AAVV. Las dimensiones internacionales del Derecho humanitario. Madrid: Tecnos, 1990, pp. 17-18.

2 Bettatl, Mario. Droit humanitaire. Paris: Éditions du Seuil, 2000, p. 19.

3 La tensión entre civilización y barbarie apunta también a la afirmación de un núcleo inderogable de derechos humanos como muestra del consenso universal en torno al tema. Véase SALMÓN, Elizabeth. "América Latina y la Universalidad de los Derechos Humanos». Revista Agenda Internacional, año Vl, n. ${ }^{\circ} 12$, enero-junio 1999, pp. 123-136.

4 Informe Final de la Comisión de la Verdad y Reconciliación. Tomo 1, Capítulo 4. p. 210. 
[este] procura el respeto de derechos mínimos o inderogables en caso de conflicto armado, intenta civilizarlo mediante la aplicación de principios tales como el respeto a la población civil, la atención y cura de heridos, el trato digno a las personas prisioneras y la protección de los bienes indispensables para la supervivencia. Esta normativa, crea un espacio de neutralidad en la medida en que pretende disminuir las hostilidades, minimiza sus efectos sobre la población civil y sus bienes y busca un trato humanitario para los combatientes, heridos o prisioneros. ${ }^{5}$

Desprovisto, por tanto, de cualquier papel legitimador, no corresponde al DIH determinar las situaciones en que resulta válido el recurso a la fuerza armada, es decir, el ius ad bellum (o derecho a hacer la guerra). En efecto, será el derecho internacional general el que contiene tales previsiones, prohibiéndola de manera general (artículo 2, inciso 4, de la Carta de las Naciones Unidas) o permitiéndola, de manera excepcional, en situaciones de legítima defensa frente a un ataque armado (artículo 51 de la Carta de las Naciones Unidas) o cuando el propio Consejo de Seguridad decide su uso frente a una amenaza a la paz, quebrantamiento de la paz o acto de agresión (capítulo vir de la Carta de las Naciones Unidas). ${ }^{6}$ Por su parte, será la legislación interna de los Estados la que regule las situaciones de insurgencia interna, habilitándola (por ejemplo para la «defensa del orden constitucional" como lo prescribe el artículo 46 de la Constitución Política del Perú de 1993$)^{7}$ o prohibiéndola (como actos que afrentan la ley y el orden interno). En conclusión, la situación de conflicto armado, cualesquiera sean sus causas, genera la obligación de aplicar las normas humanitarias, lo que, en última instancia, equivale a aceptar que ninguna situación de conflicto armado justifica la comisión de actos de violencia contrarios a las normas del DIH.

En consonancia con estos objetivos, el Estado peruano decidió ratificar los Convenios de Ginebra de 1949, ${ }^{8}$ mediante Resolución Legislativa 12412

5 Comisión para el Esclarecimiento Histórico de Guatemala. Informe 1996. Capítulo II, volumen II, parágrafo 36.

6 En el marco del Derecho internacional general el empleo del uso de la fuerza ha sido prohibido, es decir, la comunidad internacional ha pasado del ius ad bellum al ius contra bellum. Al respecto, véase el estudio especializado de la profesora MÁRQUEZ CARRASCO, María del Carmen. Problemas actuales sobre la prohibición del recurso a la fuerza en Derecho internacional. Madrid: Tecnos, 1998.

7 Artículo 46.- Nadie debe obediencia a un gobierno usurpador, ni a quienes asumen funciones públicas en violación de la Constitución y de las leyes. La población civil tiene el derecho de insurgencia en defensa del orden constitucional. Son nulos los actos de quienes usurpan funciones públicas.

8 Convenio I: Para aliviar la suerte que corren los Heridos y los Enfermos de las Fuerzas Armadas en Campaña. Convenio II: Para aliviar la suerte que corren los Heridos, los Enfermos y los Náufragos de las Fuerzas Armadas en el Mar. Convenio IIl: Trato debido a los Prisioneros de Guerra. Convenio IV: Protección debida a las Personas civiles en tiempo de guerra. 
del 31 de octubre de 1955, que surtió efectos jurídicos a partir del 15 de agosto de 1956. Desde este momento, el Perú asumió un conjunto de obligaciones aplicables a todos los conflictos armados, incluyendo los conflictos armados no internacionales, al menos en su formulación esencial del artículo 3 común a los cuatro Convenios de Ginebra. Posteriormente, el Estado peruano decidió ampliar estas obligaciones al ratificar, mediante Resolución Legislativa 25029 del 23 de mayo de 1989, los Protocolos Adicionales I y II a los Convenios de Ginebra que entraron en vigor para nuestro país el 14 de enero de $1990 .{ }^{9}$ Todas estas normas humanitarias forman parte del ordenamiento jurídico nacional, y su cumplimiento, al ser instrumentos jurídicamente vinculantes, resulta plenamente exigible. En el marco de los conflictos internos, esto significa que el Estado peruano asumió soberanamente el compromiso de que, para luchar contra un grupo de rebeldes en su territorio, solo recurriría a "medios legítimos", y que los imperativos de la seguridad del Estado no podrían justificar las violaciones de las normas humanitarias.

Por el contrario, no significa una renuncia a la legítima función estatal de restablecer el orden interno frente a una situación de violencia, ya que el DIH tiene una finalidad exclusivamente humanitaria que no pretende ese objetivo ni deroga, en consecuencia, las disposiciones internas punitivas. Quienes se enfrentan a las fuerzas gubernamentales, conformemente, no se encuentran exentos de comprometer su responsabilidad penal de acuerdo al derecho interno del Estado concernido o incluso, al igual que las fuerzas estatales, del propio derecho internacional humanitario si, de acuerdo a la visión contemporánea, se cometieran actos calificados como crímenes de guerra. ${ }^{10}$

En este sentido el propio artículo 3 común establece en su último párrafo que la aplicación del mismo no surtirá efectos sobre el estatuto juridico de las partes en conflicto. Esta disposición resulta esencial porque subraya que:

[...] el hecho de aplicar el artículo 3 no constituye en sí mismo ningún reconocimiento de poder alguno a la parte adversa; no limita de ningún modo su derecho -que le confiere su propia ley_ a reprimir una rebelión por todos los medios, incluido el uso de las armas; no afecta en nada a su derecho a perseguir judicialmente, juzgar y condenar a sus adversarios por sus crímenes, de conformidad con la propia ley. ${ }^{11}$

9 Protocolo Adicional I relativo a la protección de las víctimas de los conflictos armados internacionales. Protocolo Adicional II relativo a la protección de las víctimas de los conflictos sin carácter internacional.

10 Véase el artículo 8 inciso $2 c$ del Estatuto de la Corte Penal Internacional, que entró en vigor el 1 de julio de 2002, que establece la posibilidad de cometer crímenes de guerra en el marco de un conflicto armado no internacional.

"JUNOD, Sylvie-Stoyanka. Comentarios del Protocolo del 8 de junio de 1977 adicional a los Convenios de Ginebra del 12 de agosto de 1949 relativo a la Protección de las 
De igual manera, el inciso 1 del artículo 3 del Protocolo II precisamente establece: «No podrá invocarse disposición alguna del presente Protocolo con objeto de menoscabar la soberanía de un Estado o la responsabilidad que incumbe al gobierno de mantener o restablecer la ley y el orden en el Estado o de defender la unidad nacional y la integridad territorial del Estado por todos los medios legítimos". Si a esto se agrega el hecho de que en el derecho de los conflictos armados (o en el derecho de los derechos humanos) el que algo no esté prohibido no significa que esté permitido, resulta necesario trazar una línea entre el control de la actividad criminal y terrorista, que se rige por el Derecho interno del Estado concernido, y la función de plasmar límites a la violencia, propia del Derecho internacional humanitario. ${ }^{12}$

Si bien es cierto que la violencia contra personas y destrucción de la propiedad son inherentes al conflicto, el derecho internacional humanitario ni otorga una carta blanca a las partes para recurrir a cualquier forma concebible de violencia (como, por ejemplo, aterrorizar a la población civil), ${ }^{13}$ ni pretende sustraer la competencia estatal de preservar el orden al interior de un Estado. Por ello, si la situación equivale a un conflicto armado interno, se aplican las disposiciones normativas nacionales y también el Derecho internacional humanitario. ${ }^{14}$

Así también lo indica el informe final de la CVR, al señalar, con relación a la aplicación del derecho interno dentro de un conflicto armado no internacional (en adelante CANI), que «la aplicación del DIH durante un conflicto armado interno no afecta el estatuto jurídico nacional o internacional de los grupos insurgentes o grupos armados ni tampoco el de sus miembros" ${ }^{15}$ y que "la ley nacional permanece en vigor, es decir, que subsiste el derecho de las autoridades a perseguir y condenar eventualmente a las personas reconocidas culpables de infracciones en relación con el conflictom. ${ }^{16}$

En cuanto a la coexistencia con el derecho internacional de los derechos humanos, la CVR hace explícito que:

La aplicación del DIH no excluye en modo alguno la aplicación concurrente de tratados o de otras fuentes del Derecho Internacional de los Derechos Humanos, toda vez que dichos tratados y normas se aplican aun durante los conflictos arma-

Víctimas de los Conflictos Armados sin carácter internacional (Protocolo II) y del artículo 3 de estos Convenios. Bogotá: CICR, Plaza \& Janés, 1998, p. 349.

12 Véase GASSER, Hans-Peter. "Acts of terror, «terrorism" and International Humanitarian Law». Revista del C/CR, 2002, vol. 84, n. ${ }^{\circ} 847$, pp. 547-570.

13 Ibidem, p. 554.

14 David, Eric. Principes de Droit des conflits armés. Bruxelles: Bruylant, 1994, p. 28.

15 Informe Final de la Comisión de la Verdad y Reconciliación, Tomo 1, Capítulo 4, p. 213.

16 Ibidem, p. 213. 
dos. Sin embargo, las normas de derechos humanos y la determinación de las eventuales violaciones de los mismos, durante un conflicto armado, requieren de la aplicación concurrente de un derecho especializado como es el DIH. ${ }^{17}$

Es más, el Informe Final considera que ambas ramas del derecho internacional deben ser aplicadas de manera conjunta, al señalar que «la CVR considera imprescindible, para la calificación de ciertos actos como crímenes y violaciones de los derechos humanos, la aplicación concurrente del Derecho Internacional de los Derechos Humanos y del Derecho Internacional Humanitario». ${ }^{18}$

De esta manera, el Informe Final aporta claridad en este tema, al enfatizar que la aplicación del DIH no implica que se suspenda la aplicación del Derecho internacional de los Derechos Humanos, si bien este último se aplica en el contexto de un conflicto armado en una forma más limitada y que tampoco se sustituye la aplicación del Derecho interno.

\section{El conflicto armado interno en el Perú}

La CVR señala expresamente que la situación de violencia por la que atravesó el Perú en la década de los ochenta y noventa constituye un conflicto armado interno, al que se le aplica el artículo 3 común de los Convenios de Ginebra de 12 de agosto de 1949. En este sentido afirma que: «[...] los hechos examinados - decenas de miles de personas muertas en un contexto de violencia armada y varios otros miles de heridos o mutilados- no pueden explicarse sino por la existencia de un conflicto armado interno regido sin duda por el artículo 3 común precitado». ${ }^{19}$

Asimismo, el Informe Final considera, «que el artículo 3 común a los Convenios de Ginebra constituye el marco normativo adecuado para la determinación del núcleo inderogable de derechos vigentes durante un conflicto armado interno". No obstante, creemos que faltó claridad al señalarse conjuntamente que: «Ello no será en modo alguno obstáculo para aplicar las disposiciones del Protocolo II, en lo que resulta compatible y pertinente». ${ }^{20}$ En primer lugar, la aplicación del Protocolo Adicional II a los Convenios de Ginebra, también ratificado por nuestro país, resulta aplicable a lo que se ha denominado "conflictos de alta intensidad" por las características

\footnotetext{
$17 \quad$ Ibidem, p. 212.

$18 \quad$ lbidem, p. 213.

19 Ibidem.

o Ibidem, p. 214.
} 
que exige como control territorial o capacidad de sostener operaciones militares sostenidas y concertadas, entre otras, que a nuestro juicio no se presentaron en la situación peruana. En segundo lugar, el informe peca de imprecisión al afirmar que este protocolo será aplicable en lo que resulte "compatible y pertinente». Ciertamente, más que compatibilidad y pertinencia, de lo que se trata es de la aplicación eventual de algunas disposiciones del Protocolo II que han alcanzado el carácter de normas consuetudinarias o reflejan principios de alcance universal, que deben aplicarse a cualquier situación de conflicto armado, más allá de su caracterización jurídica.

En cualquier caso, la aplicabilidad del artículo 3 común no genera ningún problema debido a que el Perú es Parte de los Convenios de Ginebra desde 1955. Sin embargo, dicho artículo sería aplicable inclusive si se diera el caso de que el Perú no haya ratificado los Convenios de Ginebra, ya que hoy en día se considera que dicho artículo, al proteger derechos fundamentales y contener la protección a normas de ius cogens, contiene un carácter consuetudinario y por lo tanto debe ser respetado por todo Estado, más allá de que este último haya ratificado o no los Convenios de Ginebra. De esta manera, el artículo 3 común consagra una serie de derechos fundamentales, no derogables bajo ninguna circunstancia, y recoge el núcleo duro de derechos humanos plasmados en varios tratados internacionales sobre derechos humanos. La CVR ratifica esta idea al señalar que "Durante los conflictos armados internos, el artículo 3 común a los Convenios de Ginebra establece un núcleo intangible de derechos que coincide en lo esencial con lo dispuesto por las convenciones de derechos humanos antes mencionadas». ${ }^{21}$

La aplicación del artículo 3 común y sus principios resulta incondicional, inmediata y no recíproca, por ello recurrir a estas normas cumple también un papel clarificador de lo que sucedió en nuestro país. En efecto, la aplicación del DIH a estos hechos ocurridos entre mayo de 1980 y noviembre de 2000 implica el reconocimiento de al menos tres circunstancias. La primera es que los grupos armados que se enfrentaron al Estado realizaron una labor organizada y continuada que superó el nivel de escaramuzas o actos esporádicos de violencia, es decir, que generó un conflicto armado interno. La segunda es que, como consecuencia de esto, el Estado peruano debió hacer frente a una situación de extrema gravedad y dificultad debido al propio comportamiento de estos grupos que no respondía a la lógica de la guerra convencional. Y la tercera es que el Estado no se encontraba suficientemente preparado, ni táctica ni jurídicamente, para combatir a los grupos que actuaron en este periodo.

${ }^{21} \quad$ Ibidem, p. 216. 


\section{El artículo 3 común a los Convenios de Ginebra como derecho aplicable}

El DIH distingue entre un conjunto acabado y complejo de normas aplicables a los conflictos armados internacionales (compuesto por los cuatro Convenios de Ginebra y el Protocolo Adicional I) y un número menos abundante y más sencillo de normas llamadas a ejecutarse en el marco de los conflictos armados no internacionales (artículo 3 común a los cuatro Convenios de Ginebra y el Protocolo Adicional II). La aplicabilidad de estas últimas se encuentra en función de la intensidad del conflicto interno, de tal manera que habrá conflictos que se regularán por el artículo 3 común, y otros en los que existe un elemento de control territorial y nivel de enfrentamientos armados abiertos y continuados, a los que se les aplicará el artículo 3 común y el Protocolo Adicional II.

Estas normas guardan una relación asimétrica. En efecto, mientras el Protocolo Adicional II establece un conjunto de disposiciones que apuntan a una regulación más completa del conflicto (instaurando protección especial para las víctimas de los conflictos o el compromiso de procurar la concesión de amnistía al final del mismo) establece también, sin embargo, un umbral de aplicación alto y estricto que muy pocos conflictos superan. ${ }^{22}$ Por su parte, el artículo 3 común no establece condiciones precisas de aplicación, pero sus disposiciones solo apuntan a los excesos mayores de la violencia interna, estableciendo normas mínimas de respero. Su contenido, por lo demás, coincide con las disposiciones inderogables, incluso en tiempo de uguerra, peligro público de otra emergencia que amenace la independencia o seguridad del Estado" (artículo 27 de la Convención Americana sobre Derechos Humanos) o "situaciones excepcionales que pongan en peligro la vida de la nación" (artículo 4 del Pacto Internacional de Derechos Civiles y Políticos) ${ }^{23}$-el denominado núcleo duro de los derechos humanos- de las principales convenciones internacionales sobre derechos humanos. Este incluye derechos como el de la vida o el de no ser torturado, por señalar algunos sobre los que existe un innegable consenso universal.

El arrículo 3 común se refiere a la existencia de un conflicto armado que se desarrolla en el territorio de una de las Altas Partes Contratantes. En cuanto a lo primero, se entiende que existe un conflicto armado cuando se

22 Para DAviD, op.cit., p. 114, solo una guerra civil clásica como la guerra de secesión americana (1861-1865) o la española (1936-1939) parecen encajar en este instrumento. Otros ejemplos serían los de El Salvador, Eritrea, Filipinas, Yugoslavia y Georgia. 
recurre a la fuerza entre Estados o hay una situación de violencia armada prolongada entre autoridades gubernamentales y grupos armados organizados o entre estos grupos dentro de un Estado. ${ }^{24}$ En cuanto a lo territorial, la única condición es que el conflicto se desarrolle en el territorio de un Estado parte de los Convenios de Ginebra, pero no se exige un control territorial determinado o duradero ni un número específico de operaciones militares o de víctimas. En el Perú se cumplieron estas dos circunstancias mínimas, por lo que resulta adecuada la aplicación de una norma que, como el artículo 3 común, "no depende de ninguna declaración o de un cumplimiento correlativo, porque se fundamenta en principios humanitarios y no en la existencia previa de otros requisitos ni en la capacidad de los contendientes para observarlos: su aplicación es incondicional, inmediata y no recíprocam. ${ }^{25}$

En este sentido, el texto del artículo 3 común establece:

En caso de conflicto armado que no sea de índole internacional y que surja en el territorio de una de las Altas Partes Contratantes, cada una de las Partes en conflicto tendrá la obligación de aplicar, como mínimo, las siguientes disposiciones:

1) Las personas que no participen directamente en las hostilidades, incluidos los miembros de las fuerzas armadas que hayan depuesto las armas y las personas puestas fuera de combate por enfermedad, herida, detención o por cualquier otra causa, serán, en todas las circunstancias, tratadas con humanidad, sin distinción alguna de indole desfavorable basada en la raza, el color, la religión o la creencia, el sexo, el nacimiento o la fortuna o cualquier otro criterio análogo.

A este respecto, se prohíben, en cualquier tiempo y lugar, por lo que atañe a las personas arriba mencionadas:

a) Los atentados contra la vida y la integridad corporal, especialmente el homicidio en todas sus formas, las mutilaciones, los tratos crueles, la tortura y los suplicios;

b) la toma de rebenes;

c) Los atentados contra la dignidad personal, especialmente los tratos bumillantes $y$ degradantes;

d) Las condenas dictadas y las ejecuciones sin previo juicio ante un tribunal legitimamente constituido, con garantias judiciales reconocidas como indispensables por los pueblos civilizados.

${ }^{24}$ Tribunal Penal Internacional para la Ex Yugoslavia. Sentencia del caso Tadic del 7 de mayo de 1997, parágrafo 628.

25 Comisión para el Esclarecimiento Histórico de Guatemala. Informe 1996. Capítulo II, Volumen II, parágrafo 1693. 


\section{2) Los heridos y los enfermos serán recogidos y asistidos.}

Un organismo humanitario imparcial, tal como el Comité Internacional de la Cruz Roja, podrá ofrecer sus servicios a las Partes en conflicto.

Además, las Partes en conflicto harán lo posible por poner en vigor, mediante acuerdos especiales, la totalidad o parte de las otras disposiciones del presente Convenio.

La aplicación de las anteriores disposiciones no surtirá efectos sobre el estatuto jurídico de las Partes en conflicto.

El artículo 3 común contiene disposiciones que constituyen reglas básicas de convivencia que no deben romperse ni siquiera en un contexto de conflicto armado sea este interno o internacional. ${ }^{26} \mathrm{El}$ artículo plasma principios humanitarios que "constituyen el fundamento del respeto a la persona humana en caso de conflicto armado sin carácter internacional", ${ }^{27} \mathrm{y}$ reviste además un claro carácter consuetudinario por cuanto refleja las exigencias elementales de humanidad que deben ser respetadas en toda circunstancia ${ }^{28}$ y que han adquirido valor de reglas imperativas o jus cogens en la comunidad internacional. ${ }^{29} \mathrm{Su}$ aplicación en los sucesos de violencia que afectaron a nuestro país (comprendidos entre mayo de 1980 y noviembre

26 Así lo entendió la Corte Internacional de Justicia en el Caso de las Actividades Militares y Paramilitares en y contra Nicaragua, junio de 1986, parágrafo 98.

27 Preámbulo del Protocolo Adicional II a los Convenios de Ginebra del 12 de agosto de 1949 relativo a la protección de las Víctimas de los Conflictos Armados sin carácter internacional. Por su parte, PICTET, Jean. Desarrollo y Principios del derecho internacional humanitario. Ginebra: Instituto Henry Dunant, 1986, pp. 75-86, señala que el artículo recoge directamente algunos principios, como: a) el que enuncia el deber de tratar con humanidad a todas aquellas personas que no participan directamente en las hostilidades; b) el principio de no discriminación, que no excluye la posibilidad de hacer distinciones de carácter favorable basadas en el sufrimiento, el desamparo o la debilidad natural de ciertas personas o de ciertas categorías de personas; c) el principio de inviolabilidad, que se basa en la prohibición absoluta ("en cualquier tiempo y lugar») de los atentados contra la vida o la integridad corporal y contra la dignidad de la persona; d) el principio de seguridad, que prohíbe actos como la toma de rehenes o las condenas dictadas y las ejecuciones efectuadas sin previo juicio por un tribunal que ofrezca las suficientes garantías.

23 Tribunal Penal Internacional para la ex Yugoslavia. Sentencia del caso Tadic del 7 de mayo de 1997. párrafos 611 y 612.

29 De acuerdo al artículo 53 de la Convención de Viena sobre el Derecho de los Tratados de 23 de mayo de 1969, una normas ius cogens o imperativa de Derecho internacional general es uuna norma aceptada y reconocida por la comunidad internacional de Estados en su conjunto como norma que no admite acuerdo en contrario y que sólo puede ser modificada por una norma ulterior de Derecho internacional general que tenga el mismo carácter». 
del 2000) genera consensos en la medida que se trata, de un lado, de normas que, en gran parte, formaban parte del acervo jurídico nacional y, de otro, se encontraban también contenidas en instrumentos internacionales de derechos humanos y de DIH de los que el Perú era parte y, adicionalmente, del derecho internacional consuetudinario aplicable a estos casos.

\section{Otros principios esenciales aplicables a los conflictos armados no internacionales}

El artículo 3 común a los Convenios de Ginebra no contiene normas sobre la conducción de hostilidades pero, como todo el DIH, se inspira en un conjunto de principios humanitarios que tienen una importancia capital pues, como afirma Pictet, "expresan la sustancia del tema" y "sirven de líneas directrices en los casos no previstos". ${ }^{30}$

Por esto, acertadamente señala el informe de la CVR que:

[...] en cualquier tipo de conflicto armado son de aplicación no sólo las normas antes mencionadas, sino también ciertos principios inderogables del DIH que se enunciaron en el siglo XIX (cláusula de Martens). Así, la protección de la población civil está en relación con los "principios de humanidad» que fundan el principio de distinción entre combatientes y no combatientes, así como el relativo a la proporcionalidad entre las ventajas militares que se pueden alcanzar y los daños a civiles que en ningún caso deben ser excesivos. ${ }^{31}$

Los principios pueden encontrarse expresamente formulados en los Convenios (como el referente a la distinción entre combatientes y población civil contenido en el artículo 48 del Protocolo Adicional I), figurar de manera implícita (cuando el artículo 3, partiendo de la obligación de distinción, protege a las personas que no participen directamente en las hostilidades) o encontrarse en la costumbre internacional (como la Cláusula Martens que establece que "las personas civiles y los combatientes siguen estando bajo la salvaguardia y bajo el dominio de los principios del Derecho de gentes, según resultan de los usos establecidos, de los principios de humanidad y de las exigencias de la conciencia pública", presente también en el Preámbulo del Convenio de La Haya sobre medios y métodos de combate de 1907, en los artículos 63, 62, 142 y 158 de los cuatro Convenios de Ginebra respectivamente y en el artículo 1 del Protocolo Adicional I). En esta medida, los principios representan el mínimo de humanidad aplicable

30 PICTET, op.cit., p. 71.

31 Informe Final de la Comisión de la Verdad y Reconciliación. Tomo I, Capítulo 4, p. 211. 
en todo tiempo, en todo lugar y en toda circunstancia, válidos incluso para los Estados que no sean partes en los Convenios, dado que expresan la costumbre de los pueblos. ${ }^{32}$

Ahora bien, estos principios no pretenden reemplazar las normas convencionales, sino guiar su interpretación dándole el sentido más acorde con el objetivo mayor del $\mathrm{DIH}$, que no es otro que el de proteger a las víctimas de los conflictos. Tanto las normas aplicables a los conflictos internacionales como a los internos contienen principios y finalidades comunes que consisten en garantizar que todos los combates armados sean militarmente eficaces, pero sobre todo que sean librados humanamente.

En el marco de los conflictos armados no internacionales, resulta por tanto necesario recurrir no solo a la letra del artículo 3, sino también aplicar los principios del DIH. La lógica del enfrentamiento armado precisa de algunas reglas elementales (como las del artículo 3 común), que se aplican a todos los conflictos armados, pero también requiere un conjunto de principios que, aceptando la lógica del conflicto - es decir, sin permitirlo ni prohibirlo-, reglamenten las hostilidades limitando sus efectos más penosos. ${ }^{33}$ Así lo han entendido el Tribunal para la Ex Yugoslavia, la Corte Internacional de Justicia y la Comisión Interamericana de Derechos Humanos. En efecto, la Cámara de Apelación en el caso Tadic sostuvo que «la esencia general de estas reglas - y no la reglamentación detallada - [refiriéndose a las leyes y costumbres de la guerra] es aplicable a los conflictos armados

32 Pictet, op. cit. p. 71. También la Corte Internacional de Justicia en el Caso de las Actividades Militares y Paramilitares en y contra Nicaragua, junio de 1986, parágrafo 220.

33 En el caso Tadic el Tribunal de la ex Yugoslavia, parágrafo 100, señala que con la guerra civil española comienza una etapa en la que los gobiernos confrontados a una guerra civil aceptan la aplicabilidad de ciertas normas propias del derecho internacional humanitario aplicado a los conflictos armados de carácter internacional como la prohibición del bombardeo intencionado de civiles, la prohibición de atacar objetos no militares o la norma que exige la adopción de precauciones para atacar objetivos militares para evitar daños colaterales a civiles. Por su parte, las Declaraciones de Taormina, de 7 de abril de 1990 recoge las «Normas del Derecho internacional humanitario relativas a la conducción de las hostilidades en los conflictos armados no internacionales" entre las que señala los principios de distinción, inmunidad de la población civil, prohibición de males superfluos y prohibición de la perfidia, entre otros. La Declaración de Turku de 2 de diciembre de 1990, realizada por un conjunto de expertos en estos temas reconocía un "núcleo irreductible de normas humanitarias y derechos humanos que deben respetarse en todas las situaciones y en todo momento, una red de seguridad independiente de todo argumento o excusa en el sentido de que un determinado conflicto no está contemplado en el derecho internacional" y señala también la "necesidad de respetar los principios fundamentales del Derecho humanitario internacional en todas las circunstancias». Por resolución 1994/26 la Subcomisión de Prevención de Discriminaciones y Protección de las Minorías decidió transmitir el texto de la Declaración a la Comisión de Derechos Humanos. Esta emitió un Informe en su $51^{\circ}$ Periodo de Sesiones un Informe positivo sobre esta Declaración. 
internos» ${ }^{34}$ Por su parte, la Corte Internacional de Justicia, en su Opinión Consultiva sobre la Legalidad de la amenaza o el empleo de Armas Nucleares, se ha referido, aparte de los principios generales de base contenidos en el artículo 3 común, a otros principios igualmente básicos denominados "principios cardinales" que proceden del denominado Derecho de La Haya ${ }^{35}$ y que son el principio de distinción (entre personas y bienes de carácter civil y objetivos militares), ${ }^{36}$ la prohibición de usar armas de efectos indiscriminados, la prohibición de causar daños superfluos o sufrimientos innecesarios a los combatientes y, en un plano más general, la negación del carácter ilimitado del derecho de los Estados a elegir los medios de hacer la guerra. ${ }^{37}$ Estos principios, según la Corte, son tan fundamentales para el respeto de la persona humana y para las consideraciones elementales de humanidad, que han sido aceptados de forma amplia, y ello sin perjuicio de poder constatar, a su vez, que tales reglas fundamentales se imponen a todos los Estados, hayan o no ratificado los instrumentos convencionales que las expresan, porque constituyen "principios intransgredibles del Derecho internacional consuetudinario" ${ }^{38}$ Finalmente, la Comisión Interamericana de Derechos Humanos entendió, frente al ataque de un cuartel en el norte de Argentina por parte de un grupo de estudiantes, que:

Además del artículo 3 común, los principios del Derecho consuetudinario aplicables a todos los conflictos armados exigen que las partes contendientes se abstengan de atacar directamente a la población civil y a civiles en forma individual, y que al fijar sus objetivos distingan entre los civiles y los combatientes y otros objetivos

34 También en la sentencia contra Milan Martic del 8 de marzo de 1996 el Tribunal para la Ex Yugoslavia declara la vigencia de este principio para los conflictos armados no internacionales en su párrafo 10: «En lo que se refiere al Derecho consuetudinario, la norma que establece que la población civil como tal, así los civiles individualmente considerados, no serán objeto de ataque es una norma fundamental del Derecho internacional humanitario aplicable a todos los conflictos armados».

35 Nomenclatura utilizada por el Derecho internacional humanitario para referirse al conjunto de normas que regulan los medios y métodos de combate.

36 Dentro de las normas mínimas de humanidad allí señaladas, figura una que, precisamente, consiste en la prohibición de ataques en toda circunstancia contra las personas que no participen en los actos de violencia. Véase el artículo 5 de la Declaración de normas humanitarias mínimas, conocida como Declaración de Turku, 1990.

37 ClJ, Opinión Consultiva sobre la Legalidad de la amenaza o el empleo de Armas Nucleares, Corte Internacional de Justicia, 1996, parágrafo 78 . El caso de la utilización de armas químicas contra los Kurdos en el norte de Irak resulta bastante representativo de la vigencia de esta prohibición en el marco de un conflicto armado no internacional. Caso Tadic. Parágrafos 119-124. Por su parte el artículo 5, inciso 3 de la Declaración de Turku reafirma su valor consuetudinario afirmando que «3. No deberán emplearse en ninguna circunstancia las armas y demás materiales o métodos prohibidos en los conflictos armados internacionales".

3 Clj, Opinión Consultiva, parágrafo 70. 
militares legítimos. Para amparar a los civiles de los efectos de las hostilidades, otros principios del Derecho consuetudinario exigen que la parte atacante tome precauciones para evitar o minimizar la pérdida de vidas civiles o daños a la propiedad de civiles, incidentales o colaterales a los ataques contra objetivos militares. ${ }^{39}$

El principio de distinción establece que solamente los que participan en las hostilidades (ante la inexistencia, en el marco de los conflictos internos, del estatuto jurídico de combatiente) y los objetivos militares podrán ser objeto de ataques, y no se podrá, por ende, atacar a la población civil, que en todo tiempo y circunstancia deberá ser respetada. Sin perjuicio de ello, debe siempre aplicarse a favor de combatientes y no combatientes el principio de humanidad ${ }^{40}$ que consiste en respetar y tratar a todas las personas con humanidad, tanto a los combatientes, a quienes no se les hará padecer sufrimientos innecesarios, como a los no combatientes, quienes en todo momento deberán ser tratados con humanidad.

El principio de distinción sintetiza, a su vez, otros principios que regulan los ataques, a saber: el principio de objetivo militar, el principio de proporcionalidad y el principio de necesidad militar. El objetivo militar significa que solo se podrá atacar bienes que, por su naturaleza, ubicación, finalidad o utilización, contribuyan eficazmente a la acción militar y cuya destrucción total o parcial, captura o neutralización ofrezcan una ventaja militar definida. ${ }^{41}$ El concepto es relativo en sí mismo, ya que un bien puede revestir la característica de objetivo militar y luego abandonarla o viceversa. Así, las viviendas y los bloques de apartamentos civiles no son objetivos militares a no ser que se empleen con fines militares, por ejemplo, si son utilizados como cuartel general militar, o almacenes o puestos de francotiradores o de observación. ${ }^{42}$ También los que participan en las hosti-

39 Comisión Interamericana de Derechos Humanos, Informe n. ${ }^{\circ} 55 / 97$, Informe anual 1998, parágrafo 177.

* Este principio se encuentra recogido en la Cláusula Martens arriba señalada.

${ }^{41}$ Artículo 52, inciso 2 del Protocolo Adicional 1. De acuerdo con este principio, se «exige que los ataques se limiten Isolamente] a objetivos militares", estableciéndose de esta forma una limitación sustancial al derecho de las partes a llevar cabo cualquier acción que estimen pertinentes para conseguir una ventaja militar importante, considerable o decisiva. RoGers, Anthony y Paul MAlrerbe. Derecho al Objetivo: Modelo de Manual acerca del Derecho de los Conflictos Armados para las Fuerzas Armadas. Ginebra: CICR, 2001,p. 185, párrafo 2128.1.

42 Véase Artículo 52 del Protocolo Adicional a los Convenios de Ginebra de 1949 que recoge expresamente este principio. Asimismo, véase ROGERS y MALHERBE, op.cit., p. 185. En igual sentido, la Resolución 2675 (XXV) que se aplica a todos los conflictos armados, estipula (párrafo 5) que "las viviendas y otras instalaciones usadas sólo por poblaciones civiles no deberán ser objeto de operaciones militares». En virtud del principio de la necesidad militar, solo se puede atacar un bien civil o requisarlo con 
lidades pierden los beneficios acordados a los civiles en actitud pacífica, ${ }^{43}$ aunque en casos de duda sobre la condición de una persona, se presume que esta es civil. ${ }^{44}$

En caso de duda acerca de si un bien que normalmente se dedica a fines civiles, tal como un lugar de culto, una casa $u$ otra vivienda o una escuela, se utiliza para contribuir eficazmente a la acción militar, se presumirá que no se utiliza con tal fin. ${ }^{45}$ Así lo recuerda el Protocolo I y el Tribunal Penal para la Ex Yugoslavia cuando afirma que la presencia entre la población civil de personas, cuya condición no responda a la definición de persona civil, no priva a esa población de su calidad de civil. ${ }^{46}$

Además, puede ocurrir que en la planificación de las operaciones militares se detecte que, al interior de un grupo de población civil, existen objetivos militares. Ante estas situaciones, lo que se debe evaluar es la ventaja militar que se obtendrá en caso de ataque y los daños colaterales que un eventual ataque podrían causar, toda vez que la presencia de objetivos militares y de personas que participan en las hostilidades en un lugar determinado no convierten a este y sus pobladores en objetivos lícitos. ${ }^{47}$

miras a su empleo, con finalidades militarmente necesarias. Finalmente, la Declaración de Taormina apunta (artículo A6) que «La norma general que prohíbe lanzar ataques contra la población civil implica, como corolario, la prohibición de atacar viviendas u otras instalaciones que sólo sean utilizadas por la población civil».

43 En el caso de La Tablada, la Comisión Interamericana de Derechos Humanos, Informe 55/97. 98. Periodo de Sesiones del 17 de febrero al 6 de marzo de 1998, parágrafo 178, entendió que "cuando civiles como los que atacaron el cuartel de La Tablada, asumen el papel de combatientes al participar directamente en el combate, sea en forma individual o como integrantes de un grupo, se convierten en objetivos militares legítimos. En tal condición, están sujetos al ataque directo individualizado en la misma medida que los combatientes. Por consiguiente, en virtud de sus actos hostiles, los atacantes de La Tablada perdieron los beneficios de las precauciones antes mencionadas en cuanto al ataque y contra los efectos de ataques indiscriminados o desproporcionados acordados a los civiles en actitud pacífica».

4 Protocolo Adicional I artículo 50 inciso 1. Véase además JUNOD, op.cit., p. 245.

45 Protocolo Adicional I artículo 52, inciso 3. Por su parte de la Declaración de Turku señala como prohibida "6. La privación deliberada de acceso a los alimentos, el agua potable y los medicamentos que sean necesarios".

46 Artículo 50 inciso 3 del Protocolo Adicional I.

- En caso de ignorar estas premisas en la elaboración de la operación militar e iniciar un ataque, este sería considerado un ataque indiscriminado y, como tal, prohibido en el marco de un conflicto armado. En efecto, este tipo de ataques afecta indistintamente a objetivos militares y a personas civiles o bienes de carácter civil. Así, los ataques indiscriminados, según el artículo 51, inciso 4 del Protocolo Adicional I, se caracterizan por lo siguiente: a) No están dirigidos contra un objetivo militar determinado; b) Se emplea métodos o medios de combate que no pueden dirigirse contra un objetivo militar concreto; y c) Se emplea medios o métodos de combate cuyos efectos no son posible de limitar. 
En cualquier caso, cuando se atacan objetivos militares debe respetarse además el principio de proporcionalidad ${ }^{48}$ que exige que el efecto entre los medios y métodos de combate escogidos y utilizados no sea desproporcionado con la ventaja militar que se busca obtener. Esto significa que queda prohibida toda forma de violencia que no sea indispensable para someter a la contraparte en conflicto. En efecto, cuando son atacados objetivos militares, las personas civiles y los bienes de carácter civil deben ser preservados lo más posible de daños incidentales que, además, no deben ser excesivos con respecto a la directa y concreta ventaja militar esperada de cualquier ataque contra un objetivo militar. ${ }^{49}$ Este principio, a su vez, se encuentra ligado con el principio de necesidad militar, que justifica aquellas medidas de violencia militar que son necesarias y proporcionadas para garantizar el rápido sometimiento del enemigo con el menor costo posible en vidas humanas y recursos económicos. ${ }^{50}$ Es decir, que en el transcurso de las operaciones militares solo se debe tomar las medidas necesarias para obtener el objetivo propuesto. ${ }^{51}$

En resumen, los principios de DIH aplicables a los conflictos armados no internacionales son: distinción entre los que toman parte en las hostilidades y los que no (lo que alude a la lógica de objetivos militares, necesidad militar y principio de proporcionalidad); la prohibición de ataques indiscriminados o dirigidos contra los civiles; la protección de los bienes civiles indispensables para la supervivencia y la prohibición de la perfidia o utilización de armas que causan males superfluos. Todos ellos se correspon-

- VerRI, Pietro. Diccionario de Derecho Internacional de los Conflictos Armados. Letra P. Complementario como es del principio de distinción, la proporcionalidad lleva a considerar ataques prohibidos, por indiscriminados, aquellos en los que es de prever que se causarán incidentalmente muertos y heridos entre la población civil o daños a bienes de carácter civil o ambas cosas que sean excesivos en relación con la ventaja militar concreta y directa prevista. Véase artículo 51 y 57, inciso $2 b$ del Protocolo Adicional I. Este principio se encuentra, además, recogido en el numeral 2, artículo 5 de la Declaración de Turku que establece: "Cuando el uso de la fuerza sea inevitable, será en proporción a la gravedad de la situación o del objetivo que deba lograrse". ROGERS y MALHERBE, op.cit., p. 22.

COMISIÓN INTERAMERICANA DE DERECHOS HUMANOS. Informe sobre Terrorismo y Derecho internacional humanitario. AG/RES/1906 (XXXII-0/02) de 4 de junio de 2002, p. 37, parágrafo 65.

51 El principio de necesidad militar se encuentra en el Preámbulo de la Declaración de San Petersburgo de 1868, "el único objetivo legítimo que los Estados deben proponerse durante la guerra es la debilitación de las fuerzas militares del enemigo" y "a este efecto, es suficiente poner fuera de combate al mayor número posible de hombres". Figura también en el artículo $23 \mathrm{~g}$ del Reglamento de La Haya de 1907, según el cual está prohibido "destruir o apoderarse de las propiedades enemigas, excepto en el caso en que estas destrucciones o apropiaciones sean imperiosamente reclamadas por las necesidades de la guerra». Es también un elemento de la proporcionalidad contenida en artículo 57 del Protocolo Adicional 1. 
den perfectamente con el principio de humanidad y exigencias de la conciencia pública enunciados en la Cláusula Martens.

Finalmente, no puede desconocerse que el Protocolo Adicional II, de un lado, "desarrolla y completa el artículo 3 común» - aunque «sin modificar sus actuales condiciones de aplicación" (artículo 1)-- lo que abundaría en su carácter indisociable, ${ }^{52}$ y de otro, que varias de sus disposiciones pueden considerarse como normas consuetudinarias o principios jurídicos aplicables para un mejor entendimiento de las disposiciones del artículo 3 común. Por ejemplo, el artículo 4, inciso 2, no hace más que reiterar la prohibición de atentar "contra la vida, la salud y la integridad física o mental de las personas" que son derechos plasmados en el artículo 3 así como unánimemente en los tratados internacionales universales y regionales de derechos humanos. Asimismo, este Protocolo plasma algunos principios humanitarios esenciales, como la inmunidad de la población civil (al no poder ser objeto de ataque) y, estrechamente vinculado a esto, la obligación de distinguir entre la población civil y los que participen directamente en las hostilidades (artículo 13 que recoge garantías de protección a la población civil, prohibiendo que esta sea objeto de ataques, actos o amenazas de violencia), principio que, por lo demás, se encuentra también implícitamente planteado en el marco del artículo 3. De esta manera, el contenido de esta norma internacional debe resultar «un marco de referencia válido y relevantes ${ }^{53}$ para comprender no solo lo dispuesto en el artículo 3 común, sino para identificar los otros principios que también forman parte del Derecho aplicable a los años de violencia que se vivieron en el Perú.

\section{La obligación de respetar el DIH de todas las partes en conflicto}

Las obligaciones que impone el DIH, y el artículo 3 común en específico, están dirigidas a "cada una de las partes en conflicto" y no exclusivamente al Estado. Es decir, que el grupo levantado en armas (incluso en su lucha con otros grupos y no solo contra el Estado) se encuentra obligado por estas normas, y en esa medida su cumplimiento le resulta plenamente exigible. Como afirman Sassoli y Bouvier ${ }^{54}$ esto es necesario no solamente porque las víctimas deben ser también protegidas de las fuerzas rebeldes, sino porque,

ఇ Véase JUNOD, Sylvie-Stoyanka. Comentario del Protocolo II. Bogotá: CICR, Plaza \& Janés, 1998, p. 49.

s3 Comisión para el Esclarecimiento Histórico de Guatemala. Informe 1996. Capítulo II, volumen II, parágrafo 1685 .

54 SASSOLI, Marco y Antoine BOUVIER. How does Law protect in War? Ginebra: CICR, 1999, p. 214. 
de no respetarse este principio de igualdad entre los beligerantes, el DIH tendría menores posibilidades de ser respetado por las fuerzas gubernamentales (porque no se verían protegidas por las normas humanitarias) o por las fuerzas rebeldes (porque podrían no sentirse obligadas por las mismas).

En la práctica, las Naciones Unidas también lo han entendido así desde que, por ejemplo, en los conflictos de Somalia, Bosnia-Herzegovina, Liberia, Camboya, Angola, Ruanda, Georgia, etcétera, el Consejo de Seguridad se dirigía directamente "a todas las partes, a todos los movimientos y a todas las facciones" o a "todas las partes" para solicitarles que cesaran los combates o para facilitar el desplazamiento de asistencia humanitaria a las víctimas. Incluso antes de los Convenios de Ginebra, el Consejo de Seguridad se dirigía a la Agencia Judía en Palestina o al Alto Comité Árabe para solicitarles detener las hostilidades y poner fin a los «actos de violencia, terrorismo y sabotaje». ${ }^{55}$

En igual sentido, la Comisión para el Esclarecimiento Histórico de Guatemala, basándose en la obligación de cumplir y hacer cumplir en toda circunstancia lo contenido en estas normas, señaló que "tanto los miembros del Ejército, como las organizaciones guerrilleras, tenían la obligación jurídica de respetar las normas del derecho humanitario durante todo el transcurso del conflicto armado, sin tomar en consideración la intensidad de las operaciones militares, ni la época o el lugar donde ocurrieron, ni la naturaleza de las hostilidadesm. ${ }^{56}$

Adicionalmente, debe entenderse que las normas humanitarias no solo se dirigen a los miembros de las fuerzas armadas o de los grupos, sino también a aquellos que les brindan apoyo. Todos los que actúan en nombre de una parte, incluyendo a todo el personal del Estado, deben cumplir con el $\mathrm{DIH}$ en el ejercicio de sus funciones. Esto es así porque las garantías judiciales, dirigidas a jueces, o las reglas del trato médico, dirigidas al personal de los hospitales, no tendrían el efecto deseado si este personal no fuese considerado como parte de las fuerzas que combaten.

Asimismo, y como consecuencia de lo anterior, las violaciones del DIH pueden cometerse por cualquier persona (o grupo de personas), es decir, los eventuales autores no han de reunir o poseer ninguna condición especial,

55 DAVID, op. cit., pp. 196-197. La Declaración de Turku de 1990 también prevé esta responsabilidad en su artículo 2 cuando señala que "Las presentes normas serán respetadas y aplicadas por todas las personas, grupos o autoridades, independientemente de su condición jurídica y sin ninguna discriminación de índole desfavorable».

56 Memoria del Silencio, 1996, parágrafo 51. En igual sentido la Comisión de la Verdad de El Salvador señaló que "Durante el conflicto salvadoreño, las dos partes se encontraban bajo la obligación de respetar las normas del Derecho internacional, incluidas aquellas estipuladas en el Derecho internacional de los Derechos Humanos y el Derecho internacional humanitario o en ambos» (p. 4). 
por cuanto se trata de prohibir actos que atentan contra principios esenciales de humanidad. De esta manera, podrían ser considerados tanto los que se enfrentan al Estado como los que actúen a nombre de este, vale decir, personal militar. De tal manera, la aplicación del DIH resulta general por definición, y no dirigida solo a una de las partes que se enfrentan. Incluso, y de manera más contemporánea, el Tribunal Penal para Ruanda ha entendido que también pueden cometer violaciones del DIH las personas que forman parte de la población civil o que no participan directamente en las hostilidades. ${ }^{57}$

La CVR resalta también que la aplicación del artículo 3 común corresponde tanto a agentes estatales como no estatales. En este sentido, recalca que, a diferencia de Sendero Luminoso, el Movimiento Revolucionario Tupac Amaru sí respetó, en ocasiones, el DIH. Esto lo resalta la CVR al señalar que "Por lo menos declarativamente, el MRTA reconoció la aplicación de ciertos estándares mínimos humanitarios $\mathrm{y}$, en ocasiones, respetó dichas normas". ${ }^{58}$ Contrariamente, la CVR señala que "el PCP-SL negaba que los individuos tuvieran realmente derechos por el hecho de ser seres humanos y afirmaba que toda consideración humanitaria debía ceder paso a la exigencia de tomar el poder para los sectores sociales oprimidos, a quienes decía representarn. ${ }^{59} \mathrm{El}$ punto 28 de las Conclusiones generales recoge la violación por parte de PCP-SL de los Convenios de Ginebra al señalar que

La CVR por la generalidad y sistematicidad de estas prácticas, señala que miembros del PCP-SL, y en especial su dirección nacional y su denominada jefatura, tienen directa responsabilidad por la comisión de crímenes de lesa humanidad en el marco de ataques armados contra la población civil [...]. Del mismo modo, estas conductas constituyen, a juicio de la CVR, graves infracciones a los Convenios de Ginebra, cuyo respeto era obligatorio para todos los participantes en las hostilidades. La perfidia con la que actuó el PCP-SL en el terreno, escudándose en la población civil, evitando el uso de distintivos y atacando a traición, entre otros métodos similares como el recurso a acciones terroristas, constituyó un calculado mecanismo que buscaba provocar reacciones brutales de las fuerzas del orden contra la población civil, incrementando en una forma extraordinaria los sufrimientos de las comunidades en cuyos territorios se llevaban a cabo las hostilidades.

57 Tribunal Penal para Ruanda. Case ICTR-96-4-T, Sentencia Jean-Paul Akayesu de 2 de septiembre de 1998, parágrafos 630-634, en que se condena a una persona que no formaba parte de las fuerzas armadas ruandesas por violaciones del artículo 3 común y Protocolo Adicional II. 
Finalmente, con respecto a la actuación de las Fuerzas Armadas, la CVR reconoce que, en ocasiones, también violaron disposiciones del DIH. Así lo establece el punto 55 de las conclusiones generales del Informe Final de la CVR, al indicar que «La CVR afirma que en ciertos lugares y momentos del conflicto, la actuación de miembros de las FFAA no sólo involucró algunos excesos individuales de oficiales o personal de tropa, sino también prácticas generalizadas y/o sistemáticas de violaciones de derechos humanos, que constituyen crímenes de lesa humanidad así como transgresiones de normas del DIH».

El capítulo 4 del informe final recalca ello al señalar que «los derechos y prohibiciones enunciados por el artículo 3 común —uyo ámbito de aplicación comprende cualquier tipo de conflicto armado interno- obligan a los agentes estatales y no estatales en todo tiempo y lugarn. ${ }^{60}$ En cuanto a su contenido, la CVR precisa que «Existe un nivel mínimo de tratamiento humanitario que la comunidad internacional exige que sea siempre respetado, aún en las circunstancias más extremas. Y, bajo ciertas condiciones, las infracciones antes señaladas constituyen crímenes internacionales imputables a los individuos sin excepción algunam. ${ }^{61}$

En efecto, en el caso del Perú, tanto las Fuerzas Armadas como Sendero Luminoso y el Movimiento Revolucionario Túpac Amaru se encontraban obligadas por estas normas de DIH. De acuerdo al Informe Final, a lo largo del conflicto se sucedieron una serie de enfrentamientos entre Sendero Luminoso y el Movimiento Revolucionario Túpac Amaru con las fuerzas del orden que respondían a la lógica del conflicto. Se trata de ataque y defensa de objetivos militares que responden a criterios de necesidad militar y, en algunos casos, proporcionalidad. No obstante, también hay una serie de acontecimientos, relacionados temporalmente con el enfrentamiento armado, que no respetan los mínimos que la comunidad internacional establece en el artículo 3 común. En efecto, antes, durante y después del enfrentamiento armado, tanto los grupos subversivos como las fuerzas del Estado procedieron a comportamientos que violaban el contenido mínimo del artículo 3 común, como el principio de distinción entre personas que participan en el enfrentamiento y las que no (con una serie de ataques indiscriminados a la población civil), la prohibición de la tortura y otros atentados a la integridad corporal y la dignidad del ser humano así como atentados a la vida. La población civil sufrió de manera directa los efectos del conflicto y quizá el autobús de civiles en San José, en medio del enfren-

$60 \quad$ Ibidem, p. 211.

6t Ibidem. 
tamiento armado entre Sendero Luminoso y las fuerzas armadas, ${ }^{62}$ resulte suficientemente gráfico de lo que un gran número de pobladores de diversas zonas del Perú vivieron durante los años de violencia. Adicionalmente, debe señalarse que estos comportamientos se ubicaron en varios casos en el terreno de los actos terroristas también prohibidos por el DIH. En el caso Tarata, por ejemplo, el ataque indiscriminado a tres edificios de viviendas civiles no respondía a ninguna lógica militar, sino que buscaba mediante actos de violencia indiscriminados, causar terror en la población. ${ }^{63}$

En relación con los sujetos pasivos de estas violaciones, no estamos propiamente ante lo que, en el marco de los conflictos armados internacionales, se denomina estatuto de personas protegidas. En el caso de los conflictos armados no internacionales, siguiendo lo establecido en el artículo 3 común, se menciona de manera general a todas las "personas que no participan directamente en las hostilidades" que incluye también a: a) los miembros de las Fuerzas Armadas que hayan depuesto (incluso individualmente) las armas y b) las personas puestas fuera de combate por enfermedad, herida, detención o por cualquier otra causa.

Además, es importante señalar que la expresión "persona que participa en las hostilidades" es una de las características fundamentales del DIH aplicable a los conflictos armados no internacionales y predicable tanto del artículo 3 común a los Convenios de Ginebra como del Protocolo II. Cuando estamos en el ámbito de un conflicto armado no internacional, no se alude a "combatientes", debido a que no estamos ante sujetos que gocen de un derecho a combatir. Del mismo modo, al hablar de las personas que no

62 Nos referimos a la localidad de San José, provincia de Azángaro, departamento de Puno. En efecto, miembros de Sendero Luminoso incursionaban habitualmente en las carreteras de la zona interviniendo camiones y buses de pasajeros, dando arengas a su causa y solicitando una "colaboración económica» a los presentes. Durante una de estas incursiones, llevada a cabo el 22 de abril de 1992 alrededor de las 2 de la tarde, una columna de Sendero Luminoso intervino el ómnibus en el que viajaba la señora Maruja Chambi Chambi y, como era usual, solicitaron una "colaboración económica" a todos los pasajeros. Una vez logrado su objetivo, emprendieron la retirada. En ese instante, militares de la base antisubversiva de Sollocota llegaron a la zona y la columna de Sendero Luminoso, que aún se encontraba en las inmediaciones, empezó a intercambiar disparos con los militares. El ómnibus de pasajeros quedó en el medio de la balacera, y fue objeto de disparos tanto por parte de los militares como por parte de Sendero Luminoso. Según la testigo, los senderistas habrían disparado al ómnibus presumiendo que alguno de los pasajeros los había delatado. Producto del fuego cruzado, murieron tres pasajeros. No hubo muertos entre los militares y subversivos.

63 En este sentido, el informe de la Comisión de la Verdad de Chile, pp. 184-185, señala que la acción sistemática y deliberada de francotiradores contra personas civiles, el lanzamiento deliberado y sistemático de granadas contra lugares de reunión de personas civiles, o el uso de armas que por su índole sean indiscriminadas en zonas pobladas por personas civiles bien podrían ser ataques para aterrorizar. 
participan directamente en las hostilidades, en un CANI no se está ante el estatuto de una "persona protegida" otorgado bajo un conflicto internacional. En este sentido, el informe final de la CVR maneja, en ocasiones, el término correcto de "persona que no participan directamente en los conflictos", por ejemplo al señalar que "Así, se prohíben respecto de las personas que no participan directamente en las hostilidades [...] «los atentados contra la vida y la integridad corporal, especialmente el homicidio en todas sus formas, las mutilaciones, los tratos crueles, la tortura y los supliciosmm. ${ }^{64}$ No obstante, en ocasiones se alude erróneamente al término combatientes al referirse, por ejemplo, a las disposiciones del Protocolo Adicional II. Siendo este último un instrumento que regula un tipo determinado de CANI, no es correcto emplear el término combatiente dentro del marco del mismo. Por ejemplo, con alusión a este Protocolo, el informe de la CVR señala: "Con relación a lo que este Protocolo establece, cabe recordar que la primera obligación de una fuerza armada es respetar la inmunidad de la población civil. En la guerra no es antijurídico matar a los combatientes, aún cuando estén en clara desventaja». ${ }^{65}$

En efecto, no existe un solo artículo en estas normas donde se utilice la expresión "combatiente» para referirse a aquellos que participen en las hostilidades, y ello es así porque de esta forma se trata de evitar cualquier reconocimiento de un derecho a combatir que sí asiste a aquellos que participan en conflictos armados internacionales. Tal "derecho a combatir" no se predica, en modo alguno, respecto de los rebeldes o insurgentes que se levantan en armas contra un gobierno en el interior del territorio de un Estado, porque estos serán considerados, en principio, como delincuentes, y podrán en consecuencia ser juzgados como tales. ${ }^{60}$ En consecuencia, tampoco se reconoce, en el marco de los conflictos armados no internacionales, una inmunidad jurídica especial o el estatuto de prisioneros de guerra a los que resulten detenidos en el marco del enfrentamiento. ${ }^{67}$

Esto descarta cualquier posibilidad de afirmar que el Informe Final de la CVR confería estatuto de beligerantes, prisioneros de guerra o acreedores de amnistía a los que se enfrentaron al Estado.

64 Informe Final de la Comisión de la Verdad y Reconciliación. Tomo I, Capítulo 4, p. 216.

65 Ibidem, p. 214.

w SUAREZ, David. "Los conflictos armados internos". En RodrígueZ-VILLASANTE, José Luis (coord.). Derecho internacional humanitario. Valencia: Cruz Roja Española-Tirant lo Blanch, 2002, p.466.

6 El régimen de los prisioneros de guerra se encuentra básicamente contenido en el Convenio III de Ginebra referido a los conflictos armados internacionales. Según estas disposiciones, los prisioneros de guerra son soldados que, antes de la captura, cumplían simplemente con su deber. No son, en consecuencia, criminales condenados, ni personas que necesitan adoctrinamiento o instrucción correctiva. 
En efecto, de un lado, el reconocimiento de beligerancia es una antigua institución del Derecho Internacional, que surge en el siglo XIX ante la necesidad de cubrir la falta de regulación internacional para el caso de conflictos armados internos de alta intensidad, equiparando, bajo ciertos requisitos, al grupo armado de oposición como grupo beligerante, para de esta manera aplicarles las leyes y costumbres de la guerra existentes destinadas a los conflictos armados interestatales. Dicho reconocimiento no era automático, sino que dependía exclusivamente de la voluntad del Estado involucrado. Frente a este antecedente, el artículo 3 común a los Convenios de Ginebra de 1949, aplicable a los conflictos armados internos, señala enfáticamente que su aplicación no afecta el estatuto jurídico de las partes en conflicto. ${ }^{68}$ Esta disposición resulta esencial porque subraya que:

[...] el hecho de aplicar el artículo 3 no constituye en sí mismo ningún reconocimiento de poder alguno a la parte adversa; no limita de ningún modo su derecho -que le confiere su propia ley- a reprimir una rebelión por todos los medios, incluido el uso de las armas; no afecta en nada a su derecho a perseguir judicialmente, juzgar y condenar a sus adversarios por sus crímenes, de conformidad con la propia ley ${ }^{69}$.

Esto, además, ha sido reafirmado unánimemente por la práctica internacional, que separa claramente la finalidad humanitaria del artículo 3 común con cualquier reconocimiento de beligerancia que se encuentra, por lo demás, en franco desuso en las relaciones internacionales.

En segundo lugar, una regla elemental del DIH establece que el estatuto de prisionero de guerra se aplica en caso de combatientes capturados por el adversario en conflictos armados internacionales. ${ }^{70}$ En una situación de conflicto armado interno, las personas capturadas solo son consideradas como «detenidos», y es perfectamente posible, bajo el artículo 3 común y el DIH en general, que como se ha señalado, el Estado persiga, detenga, juzgue y sancione a quienes integran un grupo armado de oposición con la única limitación de respetar las garantías judiciales claramente establecidas en multiplicidad de tratados internacionales. Por tanto, y salvo que algún opositor del Informe considere que lo sucedido en el Perú fue un conflicto

6 Véase, por ejemplo, MoIR, Lindsay. The Law of Internal Armed Conflict. Cambridge: Cambridge University Press, 2002, p. 65.

a JUNOD, Sylvie-Stoyanka. Comentarios del Protocolo II del 8 de junio de 1977 y el Artículo 3 común a los Convenios de Cinebra del 12 de agosto de 1949. Bogotá: CICR, Plaza \& Janés, 1998, p. 349.

to Véase, por ejemplo, GASSER, Hans-Peter. International Humanitarian Law. An introduction. Viena: Henry Dunant Institute / Haupt, 1993, p. 73. 
armado internacional, mal podría aplicarse el régimen de los prisioneros de guerra a los detenidos de Sendero Luminoso y el MRTA

Finalmente, debe señalarse que el artículo 3 común a los Convenios de Ginebra no establece ninguna disposición que otorgue a aquellos que se levantan en armas contra el Estado el derecho a ser amnistiados. Solo una disposición de otro tratado que no es aplicable al caso peruano y que no forma parte del marco jurídico del Informe Final, el Protocolo Adicional II a los Convenios de Ginebra de 1977 establece que las autoridades procurarán la amnistía más amplia posible a las personas que hayan tomado parte en las hostilidades. Es decir, se establece una facultad soberana del Estado - que no obligación- de evaluar la posibilidad de otorgar tal medida con la limitación adicional de que la misma no podría darse a violadores de las normas internacionales aplicables en los conflictos de este tipo, vale decir, a los que estuvieren acusados de cometer crímenes de guerra.

\section{Comentario final}

Las razones de un conflicto como el que se vivió en el Perú son complejas y sobre ellas también se pronuncia en extenso el Informe Final pero, en cuanto a la aplicación del DIH concierne, no debe perderse de vista que para analizar los efectos del mismo y sus excesos, tanto por parte de los grupos que se enfrentaron al Estado así como de los miembros de las Fuerzas Armadas y policiales, resultaba necesario contar con el marco jurídico adecuado que respondiera internamente al conjunto de obligaciones internacionales en la materia asumidas por el Perú desde 1956. Recordemos además que su difusión podría haber contribuido a una mayor conciencia de la necesidad de respetar ciertos contenidos humanitarios mínimos. Pensando en futuro, debe tenerse en cuenta que, dadas las características particulares en que las normas de DIH están llamadas a actuar, el momento más adecuado para proceder a la implementación de estas disposiciones es el tiempo de paz. Así como los aspectos militares y económicos de los conflictos son preparados en tiempos de paz, también es necesario trabajar en la adopción de estas medidas en un contexto de calma pues «una vez que el conflicto armado se desencadena, con todo el odio en el que se basa y genera, es frecuentemente muy tarde para aprender este mensajem. ${ }^{71}$ 